\title{
Is Davidson's Theory of Action Consistent?
}

\section{Robert D. Murray}

Ryerson University

digital.library.ryerson.ca/object/170

Please Cite:

Murray, R. D. (1995). Is Davidson's theory of action consistent?, Canadian Journal of Philosophy, 25(3), 317-334.

doi:10.1080/00455091.1995.10717418

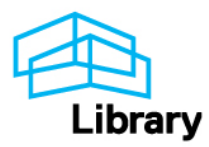




\title{
Is Davidson's Theory of Action Consistent?
}

\author{
ROBERT MURRAY \\ Erindale College \\ University of Toronto \\ Mississauga, $\mathrm{ON}$ \\ Canada L5L 1 C8 \\ and \\ Ryerson Polytechnic University \\ Toronto, ON \\ Canada M5B 2K3
}

\begin{abstract}
A theory of human action should provide an account of the connection between reason and action when an agent acts for a reason, and it should provide an account of the explanatory force of explanations of actions. On the causal theory of action, the connection between reasons and actions is that of event causality and explanations of actions are modeled on ordinary causal explanations, where events are explained by citing other events as their causes. A once common objection to the causal theory had it that reasons cannot be causes, since explanations of actions do not fit reason and action into a nomic nexus expressed by laws or law-like generalizations. Against this train of thought, Donald Davidson defends a version of the causal theory by arguing that the view that the connection between reasons and actions is that of event causality and the view that explanations of actions do not fit reasons and actions into a nomic nexus are compatible. Davidson's theory generated a small industry of criticism focusing on the implications of his version of the causal theory for the nature of the causal connection between reasons and actions. ${ }^{1}$ This criticism is related to the original criticism of the causal
\end{abstract}

1 Examples include Ted Honderich, 'The Argument for Anomalous Monism,' Analysis 42 (1982) 59-64; Ernest Sosa, 'Mind-Body Interaction and Supervenient Causation,' Midwest Studies in Philosophy 9 (1984) 271-81; Jaegwon Kim, 'The Myth of Nonreductive Materialism,' Proceedings of the American Philosophical Association 63 (1989) 31-47. 
theory. Rather than claiming that reasons cannot be causes if explanations of actions do not fit reason and action into a nomic nexus, however, criticism of Davidson has it that if reason explanations do not fit reason and action into a nomic nexus, then even if reasons are causes, they are not causes qua reasons. The underlying idea, apparently, is that if laws or law-like generalizations express the causal structure of nature, and reason explanations do not fit reason and action into a nomic nexus, then reasons are not causes in virtue of their mental properties. Accordingly, Davidson's position on the causal connection between reasons and actions is counter-intuitive. Echoing this criticism, Anthony Skillen refers to Davidson's theory of the connection between reasons and actions as 'linguistic epiphenomenalism.' I suggest that the focus of this criticism against Davidson should be placed elsewhere. First, we do not have a clear understanding of mental properties - that Gordian knot remains untied - and second, Davidson seems to have addressed this criticism by pointing out that causal connections hold between events independently of whether singular causal statements -- those statements citing one event as the cause of another - fail to fit cause and effect into a nomic nexus. Davidson's key point here is that causality is one thing and the way we describe events related as cause and effect is another. ${ }^{3}$ Because we have a clearer understanding of the nature of causal explanation than we have of the nature of mental properties, I suggest we shift the focus of criticism to the issue of whether Davidson's version of the causal theory provides an account of the explanatory force of explanations of actions. To decide that issue, we must determine whether explanations of actions satisfy the presuppositions of ordinary causal explanations, if explanations of actions do not fit reason and action into a nomic nexus. If they do, then Davidson's theory provides an account of the explanatory force of explanations of actions; if they do not, then his theory does not. I will argue for the latter.

Davidson's version of the causal theory of action includes the following as central tenets: (1) when an agent acts for a reason, reason and action are related as cause and effect; (2) like ordinary causal explanations, explanations of actions explain by citing events related as cause and effect; and (3) explanations of actions do not fit reason and action into a nomic nexus expressed by laws or law-like generalizations. Other proponents of the causal theory more commonly endorse tenets (1) and

2 'Mind and Matter: A Problem that Refuses Dissolution,' Mind 93 (1985), 520

3 Davidson responds to this criticism in 'Thinking Causes,' in John Heil and Alfred Mele, eds., Mental Causation (Oxford: Clarendon 1993). 
(2), although some introduce special mental events like volitions as causal intermediaries between reasons and actions, but reject tenet (3); instead, they hold the opposite view that explanations of actions do fit reason and action into a nomic nexus. Included here are David Hume, John Stuart Mill, Ernest Nagel, and Carl Hempel, who maintain that the laws or law-like generalizations of the nomic nexus are expressed in the vocabulary of explanations of actions. Included, too, are Wilfrid Sellars, Jerry Fodor, and William Lycan, who maintain that the laws or law-like generalizations of the nomic nexus are partly expressed in the vocabulary of the natural sciences.

Following Davidson, I will refer to explanations of actions as reason explanations or rationalizations, and to the explanatory factors cited by such explanations as reasons. In this context a reason consists of a complex psychological state corresponding to the premises of a practical syllogism: a belief-desire pair, a hunch-fear pair, or the like. On the causal theory, since the action corresponds to the conclusion of a practical syllogism, and the reason for the action to its premises, citing the reason for an action provides a rationale for the action and causally explains the action. On Davidson's view, reason explanations differ from ordinary causal explanations in two respects: (i) reason explanations provide the rationale for the events they causally explain; and (ii) reason explanations do not fit cause and effect into a nomic nexus. It is the latter point that makes Davidson's version of the causal theory novel and theoretically interesting. On those versions of the causal theory on which reason explanations do fit reason and action into a nomic nexus, reason explanations differ from ordinary causal explanations in the first respect, but not in the second.

Many philosophers argue that if reason explanations do not fit reason and action into a nomic nexus, then reasons and actions are precluded from being related as cause and effect. Tenets (1) and (3), by their understanding, seem incompatible. Accordingly, some reject tenet (3) in favor of the causal theory ${ }^{4}$; others, taking it as plain that tenet (3) is true, reject the causal theory. ${ }^{5}$ By arguing that reasons and actions can be related as cause and effect, even if reason explanations do not fit reason and action into a nomic nexus, Davidson seems to have shown that a causal theory of action is compatible with the view that reason explana-

4 See, for example, Ernest Nagel, The Structure of Science (New York: Harcourt, Brace \& World 1961), esp. 555.

5 See, for example, William Dray, Laws and Explanations in History (Oxford: Oxford University Press 1957), Ch. 5. 
tions do not fit reason and action into a nomic nexus. In this paper I do not take issue with the position that tenets (1) and (3) are compatible as Davidson argues; I am not primarily concerned here with the issue of whether reasons and actions are related as cause and effect. Instead, I argue that, given a widely defended position concerning the presuppositions of ordinary causal explanations, tenets (2) and (3) are incompatible. If I am right, then Davidson's version of the causal theory is both inconsistent and fails to provide an account of the explanatory force of reason explanations.

My argument is a simple one appealing to the difference between reason explanations and ordinary causal explanations regarding their relations to a nomic nexus. There are several arguments for the view that the explanatory force of ordinary causal explanations derives from their relations to a nomic nexus. Davidson himself endorses such a view. ${ }^{6}$ On the other hand, he rejects the view that the explanatory force of reason explanations derives from their relations to a nomic nexus. ${ }^{7}$ This turns out to be a problem for Davidson because, as stated in tenet (2), he maintains that by citing events related as cause and effect, reason explanations illustrate the same pattern of explanation as do ordinary causal explanations. ${ }^{8}$ It is not clear how his position could be consistent if reason explanations do not satisfy the presuppositions of ordinary causal explanations. To appreciate how this problem arises for Davidson, one must know which intuitions underlie his theory. The basic intuition behind the causal theory is that when an agent acts for a reason, reason and action are causally connected. According to Davidson, this causal connection is the familiar one of event causality. A second intuition behind Davidson's theory is the Kantian idea that explanations of actions do not fit reason and action into a nomic nexus. The latter underlies his wellknown claim that mental events are anomalous. To understand how Davidson works out the relation between these two intuitions, we must appreciate the following: Davidson's arguments that tenets (1) and (3) are compatible; his view on the relation between reason explanations

6 'Agency,' reprinted in Donald Davidson, Essays on Actions and Events (Oxford: Clarendon 1980), 52-3. Unless indicated otherwise, all page references to works by Davidson are to this book.

7 'Actions, Reasons, and Causes,' 15-16; 'Hempel on Explaining Action,' 264; 'Problems in the Explanation of Action,' in P. Pettit, R. Sylvan, and J. Norman, eds., Metaphysics and Morality: Essays in Honor of J.J.C. Smart (Oxford: Basil Blackwell 1987), 42

8 'Actions, Reasons, and Causes,' 10 . Hereafter this article will be referred to as 'ARC.' 
and causal laws and causal lore; and his arguments for the causal theory. In sections I to III, I will discuss these three points. In section IV, I will defend a view on the presuppositions of ordinary causal explanations, and I will argue that, since explanations of actions do not satisfy these presuppositions, tenets (2) and (3) of Davidson's theory are incompatible. In section V, I will suggest that Davidson holds the position defended in section IV.

\section{Davidson on Reasons as Causes}

The source of the apparent contradiction between tenets (1) and (3) lies in a perceived link between the Humean account of causality and the covering law model of causal explanation. According to Hume, 'we may define a cause to be an object, followed by another, and where all the objects similar to the first are followed by objects similar to the second. ${ }^{\prime 9}$ (For the purposes of this discussion I assume Davidson's view that such objects are always events.) On the Humean statement of causality, events related as cause and effect are instances of causal regularities, and thus explaining an event by citing its cause entails that events similar to the cause are followed by events similar to the effect. Prior to Davidson's work, philosophers usually took this point about causality to entail that causal explanations subsume cause and effect under laws or law-like generalizations or, equivalently, that causal explanations instantiate laws. If reason explanations do not fit reason and action into a nomic nexus, however, it seems that, as Davidson says, "laws are involved essentially in ordinary causal explanations, but not in rationalizations' (ARC, 15). How, then, given the Humean statement of causality, could the connection between reasons and actions be that of event causality?

Davidson solves the apparent contradiction between tenets (1) and (3) by understanding the Humean statement of causality as follows:

Hume's claim ... is ambiguous. It may mean that "A caused B" entails some particular law involving the predicates used in the descriptions " $A$ " and " $B$ ", or it may mean that "A caused B" entails that there exists a causal law instantiated by some true descriptions of $A$ and $B$. (ARC, 16)

9 David Hume, Enquiry Concerning the Human Understanding, 2nd ed. L.A. SelbyBigge, ed. (London: Oxford University Press 1902), 76 
His solution trades on the distinction between causality, a relation that holds between events, and causal explanation, a relation of a different type. We must, he writes,

\footnotetext{
distinguish firmly between causes and the features that we hit on for describing them, and hence between the question whether a statement says truly that one event caused another and the further question whether the events are characterized in such a way that we can deduce or otherwise infer, from laws or other causal lore, that the relation was causal. ('Causal Relations,' 155)
}

On the view that events are concrete particulars, events related as cause and effect can be described in an indefinite number of ways, and thus they can be cited in singular causal statements that fit cause and effect, as described, into a nomic nexus; as well, the same events, described differently, can be cited in singular causal statements that do not fit cause and effect into a nomic nexus. As Davidson illustrates with a wonderful example, a hurricane might cause a catastrophe, and if the hurricane is reported on page 5 of Tuesday's Times and the catastrophe is reported on page 13 of Wednesday's Tribune, then the following is a true singular causal statement: 'The event reported on page 5 of Tuesday's Times caused the event reported on page 13 of Wednesday's Tribune' (ARC, 17). There are, of course, no laws or law-like generalizations relating events of the types cited in the statement, and hence the statement does not fit cause and effect into a nomic nexus. We see, then, that whether a true singular causal statement fits cause and effect into a nomic nexus depends on how those events are described. Accordingly, the view that reasons and actions are related as cause and effect is compatible with the view that reason explanations do not fit reason and action into a nomic nexus, as long as there are descriptions, knowable or not, of the same events that could be employed to fit them into a nomic nexus. In other words, the argument, that reasons and actions cannot be related as cause and effect if reason explanations do not fit reason and action into a nomic nexus, confuses the presuppositions of the covering law model of explanation with those of the Humean account of causality. Davidson shows how a true singular causal statement might satisfy the latter without satisfying the former. It is important to note that Davidson's point on the difference between causality and causal explanation does not show that reasons and actions are related as cause and effect, but only that they are not precluded from being so related on the grounds that reason explanations do not fit reason and action into a nomic nexus. I will present Davidson's arguments for the view that reasons and actions are related as cause and effect in section III. 


\title{
II Davidson on The Relation Between Reason Explanations and a Nomic Nexus
}

In many places Davidson expresses agreement with the Kantian view that reason explanations do not fit reason and action into a nomic nexus. This point underlies his well-known claim that mental events are anomalous. In 'Mental Events,' 'Psychology as Philosophy,' and 'The Material Mind,' he argues that reason explanations do not fit reason and action into a nomic nexus expressed in the vocabulary of the natural sciences. In the earlier paper 'Actions, Reasons, and Causes,' and the later papers 'Hempel on Explaining Action,' and 'Problems in the Explanation of Action,' Davidson claims that reason explanations do not fit reason and action into a nomic nexus expressed in the vocabulary of reason explanations. He states that we do not have 'rough laws connecting reasons and actions' and that 'generalizations connecting reasons and actions are not - and cannot be sharpened into - the kind of law on the basis of which accurate predictions can reliably be made' (ARC, 15). He argues for this as follows:

\begin{abstract}
If we reflect on the way in which reasons determine choice, decision, and behavior, it is easy to see why this is so. What emerges, in the ex post facto atmosphere of explanation and justification, as the reason frequently was, to the agent at the time of action, one consideration among many, $a$ reason. Any serious theory for predicting action on the basis of reasons must find a way of evaluating the relative force of various desires and beliefs in the matrix of decision; it cannot take as its starting point the refinement of what is to be expected from a single desire. (ARC, 15-16)
\end{abstract}

According to Davidson, it is not possible to evaluate the relative forces of competing reasons and, hence, it is not possible to state rough laws in the vocabulary of reason explanations. With a clever example he reminds us that sometimes we explain a person's adulterous actions by appeal to lust, but this carries no implication for how the rest of us will act in the face of lust:

\footnotetext{
If we were to guess at the frequency with which people perform actions for which they have reasons (not necessarily adequate or good reasons, but reasons in the simple sense under consideration), I think it would be vanishingly small. (To aid your imagination: what is the ratio of actual adulteries to the adulteries which the Bible says are committed in the heart?) ('Hempel on Explaining Action,' 264)
}

The standard response to this claim has it that reason explanations only appear not to fit reason and action into a nomic nexus, since, as typically stated, reason explanations are only partial explanations or explanatory sketches. A partial explanation presupposes a complete explanation that also cites initial conditions such as further relevant beliefs, desires, and the like. In this way, it is argued, reason explana- 
tions do have implications for any agent satisfying the same initial conditions. For example, perhaps agents act out of lust if they believe the behavior will go undetected and if they believe the other party is willing, and so on. Davidson maintains that even when these further conditions are worked into a covering generalization, the explanation in question nevertheless remains idiosyncratic - it fits that specific agent only, and perhaps only for a short time. On Davidson's view, even complete reason explanations fail to have predictive implications for what other agents will do and even, he says, for what the same agent will do at a different time. Accordingly, such putative law-like generalizations - in this case, agents experiencing lust tend to commit adultery when they believe the behavior will go undetected and when they believe the other party is willing, and so on - are not really laws at all, but rather,

are peculiar to individuals, and even to individuals at particular moments. So if a vagrant fancy for a ride on the fun wheel were to flit through Dora's mind, some law like this would be true: for the space of those few moments, if Dora had believed some action of hers would have produced a ride on the fun wheel (and a lot more conditions were satisfied), Dora would have taken that action. If this is the sort of law involved in reason explanations, we all know an enormous number of highly particular laws. It does not sound like much of an argument for the possibility of a scientific psychology. (Ibid., 265)

Against this view, one might be inclined to argue that even if reason explanations do not fit reason and action into a nomic nexus, their explanatory force derives from very low grade generalizations. So that even if, to use Davidson's example, the ratio of actual adulteries to the adulteries which the Bible says are committed in the heart is extremely low, nevertheless, the case where we explain adultery by appeal to lust derives its explanatory force from the background generalization that people experiencing lust tend with some probability to commit adultery. Whatever the virtues of this model, if any, Davidson maintains that it fails to provide a plausible account of the explanatory force of reason explanations. Commenting on this very example, he writes,

While the probability may be very low, it isn't zero; and on the other side, we can say that it is (logically) impossible to perform an intentional action without some appropriate reason. So a desire (represented now by a probabilistic law) and a belief do provide at least a very low-grade statistical explanation. If the agent had the appropriate belief and desire, it was at least possible for him to perform the action to be explained, and there was some (very low) probability that he would.

This does not seem to me to give a very convincing account, however, of why we count reason explanations of actions as so meaningful - as such good explanations. It may do as well as we can do to explain why a coin comes up heads four times in a row to say, well, that does happen on average once every so often. We feel we do very much better in explaining why Ada punched those keys when we 
mention her desire and belief - far better than could be accounted for by the fact that once in a blue moon someone with those motives performs such an act. (lbid., 264)

Elsewhere, he writes,

much of the explanatory force of reason-explanations comes from the fact that they specify which pair, from among the vast number of belief-desire pairs that were suited to cause the action, actually did cause it. ('Problems in the Explanation of Action,' 42)

In these passages Davidson rejects the position that reason explanations fit reason and action into a nomic nexus, and he rejects the position that the explanatory force of reason explanations derives from their relations to a nomic nexus. On Davidson's view, reason explanations simply do not explain by fitting reason and action into a nomic nexus; as mentioned earlier, this is what makes his version of the causal theory novel and theoretically interesting.

\section{Davidson's Arguments for the Causal Theory}

Why then does Davidson think reason explanations explain by citing events related as cause and effect? His central concern in 'Actions, Reasons, and Causes' is to show that reasons and actions are related as cause and effect; he seems to take this as sufficient for showing that reason explanations illustrate the same pattern of explanation as do explanations that explain by citing events related as cause and effect. At no point does Davidson argue for the causal theory on the grounds that it has anything like the structure of causal lore where explanations fit cause and effect into a nomic nexus; indeed, as I have already discussed in section II, he holds the opposite view. His major argument for the causal theory is that the causal theory alone provides an account of the difference between the case where an agent holds reason $R$, and does action $A$ because of $R$, and the case where the agent holds $R$, but does $A$ for another reason. In each case, $\mathrm{R}$ might provide a rationale for $\mathrm{A}$, but citing $R$ provides an explanation of $A$, only in the case where the agent does $A$ because of $R$. If it is not sufficient for an agent's having performed $A$ because of $R$ that $R$ provide a rationale for $A$, then we must know what further condition must be met for the agent to have acted because of reason $\mathrm{R}$; we must know, in other words, what else besides a rationalegiving relation between $R$ and $A$ is presupposed by a reason explanation which explains A by citing $R$. On the causal theory, as well as providing a rationale for $A, R$ must cause $A$. According to Davidson, if the causal theory alone provides an account of this difference, then necessarily the 'because' of reason explanations functions to indicate that reason and 
action are related as cause and effect. Reason explanations, it is thereby revealed, like ordinary causal explanations, explain by citing events related as cause and effect (ARC, 9).

Davidson also argues that the causal theory provides the only available account of the explanatory force of reason explanations:

One way we can explain an event is by placing it in the context of its cause; cause and effect form the sort of pattern that explains the effect, in a sense of "explain" that we understand as well as any. If reason and action illustrate a different pattern of explanation, that pattern must be identified. (ARC, 10)

As well, he argues that the causal theory of action provides the only available account of the connection between reasons and actions:

I would urge, that, failing a satisfactory alternative, the best argument for a scheme like Aristotle's is that it alone promises to give an account of the "mysterious connection" between reasons and actions. (ARC, 11)

Whether or not Davidson's arguments for the causal theory provide a convincing case for the view that the connection between reasons and actions is that of event causality, they do not show that reason explanations illustrate the same pattern of explanation as do ordinary causal explanations, since they do not show that reason explanations satisfy the presuppositions of ordinary causal explanations.

\section{The Presuppositions of Causal Explanations}

We must determine whether causal explanations presuppose a nomic nexus for their explanatory force. We can decide this issue on the following grounds, I think: since one cannot causally explain an event by citing features of its cause that make no causal difference to the event in question, there is a difference between citing the cause in a way that is causally explanatory and citing the cause in a way that is not. Stating that difference will reveal a further presupposition of causal explanation, beyond the causal relation itself. This is a pressing issue for Davidson, since the view that events are concrete particulars allows for true singular causal statements that are not causally explanatory. I argue here that to be an explanation a true singular causal statement must fit cause and effect into a nomic nexus. As will be discussed shortly, my argument, though not offered in support of the covering law model, is related to an argument repeatedly employed by Hempel for the covering law model. One further point: it is important to understand that I am not expressing the criticism made by Honderich, Sosa, Kim, and others that on Davidson's theory reasons are not causes qua reasons. Rather, I am offering a 
general argument to the effect that ordinary causal explanations presuppose a nomic nexus for their explanatory force and then arguing that Davidson's version of the causal theory is inconsistent. I do not appeal to the notion of causing qua reason in my argument.

There are different models of how causal explanations presuppose a nomic nexus. On the covering law model, an explanation consists of two parts: a statement of the phenomenon to be explained, the explanandum statement, and statements of the explanatory facts, the explanans. The explanans consists of a statement of the cause, statements of any relevant initial conditions, and laws by which the explanandum is deductively or inductively inferrable from the explanans. On this model, explanations are arguments to the effect that given the explanans the phenomenon to be explained was to be expected; causal explanations, it turns out on this view, have the same logical form as predictions. The covering law model allows that several laws might be part of the explanans, but, thinks Hempel, by a purely logical point, a predictive law, L, can always be formulated such that cause and effect, as described, are subsumed under L. ${ }^{10}$ In this sense, on the covering law model, causal explanations subsume cause and effect under laws.

Of course, few explanations, as stated, meet the requirements of the covering law model. Defenders of the covering law model such as Nagel and Hempel understood themselves to be revealing the logical structure implied by valid scientific explanations; they did not take themselves to be offering a descriptive account of scientific practice. The covering law model is a model of what form a complete causal explanation must take; it states the presuppositions of valid causal explanations. A causal explanation might be an incomplete explanation, or explanatory scheme, provided it can be filled out to satisfy the requirements for complete explanation. An incomplete explanation is part of a complete explanation and is explanatory in virtue of that fact. On this point Hempel offers the following helpful parallel with mathematical proof theory:

Metamathematical proof theory is not intended to give a descriptive account of how mathematicians formulate their proofs. Indeed the formulations that mathematicians actually offer will usually depart to some extent from that called for by rigorous and, as it were, "ideal", metamathematical standards. Yet those standards may be said to exhibit the logical structure and the rationale of mathematical demonstration and to provide criteria for the critical appraisal of particular proofs that might be proposed. (Aspects, 414)

10 Aspects of Scientific Explanation (New York: The Free Press 1965), 346. Hereafter this book will be referred to as Aspects. 
As will be discussed below, the distinction between complete and incomplete explanation allows us to see that reason explanations do not satisfy the presuppositions of ordinary causal explanations on Davidson's version of the causal theory. The issue is important because we provide an account of the explanatory force of explanations of a given type by revealing their presuppositions. If reason explanations do not satisfy the presuppositions of ordinary causal explanations, then Davidson's theory does not provide an account of the explanatory force of reason explanations.

The covering law model is only one model of how causal explanations might fit cause and effect into a nomic nexus; it can be rejected, at least in part, because the requirement that causal explanations have the same form as predictions meets with a counter-example that can be handled by a different model of causal explanation that seems to have the virtues of the covering law model. Hempel argues that causal explanations have the same logical structure as predictions by appeal to a general condition of adequacy for any acceptable causal explanation:

Any rationally acceptable answer to the question "Why did event $X$ occur?" must offer information which shows that $X$ was to be expected - if not definitely, as in the case of D-N explanation, then at least with reasonable probability. Thus, the explanatory information must provide good grounds for believing that $X$ did in fact occur; otherwise, that information would give us no adequate reason for saying: "That explains it - that does show why X occurred." (Aspects, 367-8)

Objecting to this requirement, Norwood Russell Hanson argues that although the laws of quantum theory are not predictive, one can completely explain an improbable event ex post facto in terms of those laws. ${ }^{11}$ In the case that the laws of quantum theory capture all the factors that make a causal difference (surely a possibility), then even if some event $X$ was not to be expected, after its occurrence the laws of quantum theory would give us adequate reason for saying 'That explains it - that does show why X occurred.' Thus Hempel's general condition of adequacy can be satisfied by causal explanations that do not have the same structure as predictions.

The second ground offered by Hempel for the covering law model is more interesting from the point of view of our discussion. Presenting a necessary condition for causal explanation, without fully explaining why we should see it that way, Hempel argues that laws not only play

11 'On the Symmetry between Explanation and Prediction,' The Philosophical Review 68 (1959), 354 
an inferential role in complete explanations, but they are also an essential source of the explanatory force of causal explanations. He argues this point in many places; the following will serve as an example:

In the explanation of an individual occurrence, those general nomic principles are required to connect the explanandum event with other particulars, and it is by such nomic connections that the latter acquired the status of explanatory factors. ${ }^{12}$

This requirement is essential to Hempel's position because, like Davidson, he maintains that any particular or concrete event has many aspects, and thus can be described in an indefinite number of ways. When characterized in terms of one of its aspects the result is what he called a sentential event (a term Hempel offered for want of a better term) (Aspects, 421-3). The notion of a sentential event is important in the logic of explanation because when we explain an event by citing its cause we do so by considering certain aspects of cause and effect rather than others. The role of laws, we might say, is to ground the claim that putative causal explanations cite the right sentential events. In that case, causal statements that do not fit cause and effect into a nomic nexus do not have the explanatory force of causal explanations.

Of course, even if causal explanations fit cause and effect into a nomic nexus, and even if complete causal explanations must include laws, explanations of quantum phenomena provide counter-examples to the covering law model, since prediction and explanation come apart. In an illuminating discussion of the relevance of this point, Wesley Salmon explains that Hempel actually characterizes the covering law model using two different conceptions of causal explanation..$^{13}$ These conceptions correspond to the two different grounds that Hempel offers for the covering law model. Sometimes Hempel requires causal explanations to show why the phenomenon to be explained was to be expected. Such characterizations reflect what Salmon calls the 'epistemic conception of causal explanation.' In other places Hempel requires causal explanations to fit the phenomenon to be explained into a nomic nexus. Reflecting what Salmon calls the 'ontic conception of causal explanation,' Hempel characterizes his view as follows:

12 Aspects, 425. Also see pages 337, 348, 361, 363, and 369. Ernest Nagel presents the same argument in The Structure of Science, 555.

13 Scientific Explanation and the Causal Structure of the World (Princeton: Princeton University Press 1984), 369 
The central theme of this essay has been, briefly, that all scientific explanation involves, explicitly or by implication, a subsumption of its subject matter under general regularities; it seeks to provide a systematic understanding of empirical phenomena by showing that they fit into a nomic nexus. (Aspects, 488)

Relating the doctoral work of Peter Railton, Salmon points out that, as in explanations of quantum phenomena, which fit the phenomenon to be explained into a nomic nexus without showing that it was to be expected, the epistemic and the ontic conceptions of causal explanation are distinct. ${ }^{14}$ Of the two, the ontic conception is better as it deals with valid explanations that, though complete, are not of the same form as are predictions. As well as explanations in sciences like physics and the like, where the vocabulary of the explanation overlaps with that of the nomic nexus, the ontic conception of explanation applies to ordinary causal explanations and sciences like geology, meteorology, and so on, where the vocabulary of the explanation and that of the nomic nexus are quite different.

In a clear discussion of all the points relevant here, David-Hillel Ruben defends the view that causal explanations presuppose a nomic nexus and finds it related to Aristotle's criterion for when a cause is described in an explanatory way (per se cause) and not so described (incidental or accidental cause):

Aristotle, it will be recalled, thought that laws provided the criteria for the selection of the descriptions under which the explanans explains the explanandum. Why did the match light? I struck it, and my striking of the match was, let us suppose, the penultimate thing that ever happened to the match. Or, my striking of the match was the event that caused the match to light. Why, then, can I explain the fact that the match lit by the fact that the match was struck, and not by the different facts that the penultimate thing that ever happened to the match occurred, or that the cause of its lighting occurred, even though these three singular facts (the fact that the match was struck, the fact that the cause of the match's lighting occurred, the fact that the penultimate thing that ever happened to the match occurred) are all facts about the same causal event, but differently described? In virtue of which of the features of a cause is the cause fully explanatory of the effect?

Aristotle's reply would be that the explanatory features are the ones linked in a law (whether deterministic or stochastic). To be sure, that strikings of matches are followed by lightings of matches is itself no law, nor any part of a law, of nature. We must therefore extend Aristotle's point, to include not only features linked in a law, but also features nomically connected in the appropriate way in virtue of underlying laws. In virtue of the underlying laws of physics and chemistry, striking

14 Peter Railton, 'Explaining Explanation' (Diss., Princeton University, 1980). See also Railton's 'A Deductive-Nomological Model of Probabilistic Explanation,' Philosophy of Science 45 (1978), esp. 224-6. 
and lighting, but not for example being a penultimate occurrence and a lighting, are nomically related. It is not that the laws need be any part of the explanation; rather, the laws provide the criteria for determining under which descriptions one particular explains another (which singular fact explains another). Laws permit selection of the vocabulary appropriate for singular explanation. ${ }^{15}$

In the above passage, Ruben points out that one can relate ordinary causal explanations such as 'The match lit because it was struck' to a nomic nexus stated in a different vocabulary. In addition, using 'The penultimate thing that ever happened to the match caused it to light,' he illustrates that true singular causal statements fit cause and effect into a nomic nexus depending on how those events are described. Ruben's discussion of Aristotle's criterion for when a cause is described in an explanatory way (per se cause) and not so described (incidental or accidental cause) helps us appreciate that one can reformulate the criticism expressed by Honderich, Sosa, Kim, and others as a criticism focusing on whether Davidson's theory provides an account of the explanatory force of reason explanations, without confusing the presuppositions of causal explanation with those of causality. If so, we can grant Davidson his point that the causal relations of events are independent of how they are described, but nevertheless maintain that whether singular causal statements satisfy the presuppositions of ordinary causal explanations depends on how cause and effect are described.

\section{Davidson on the Presuppositions of Ordinary Causal Explanations}

These points allow us to better evaluate whether Davidson's expressed notion of causal explanation is compatible with his model of reason explanations as causal explanations. I argue that since ordinary causal explanations presuppose a nomic nexus for their explanatory force, the central tenets of Davidson's theory are inconsistent. Davidson does not argue that ordinary causal explanations do not presuppose a nomic nexus. He does argue that the covering law model of explanation is false, but, of course, that differs from showing that causal explanations do not presuppose a nomic nexus. In fact, as I will discuss, Davidson seems to endorse a model of ordinary causal explanation closely resembling the

15 Explaining Explanation (London: Routledge 1990), 205-6. See pages 87-93 for his complete discussion of Aristotle's distinction between per se cause and incidental cause. 
ontic conception of causal explanation. It is also worth reminding ourselves that Davidson does not make a special case for reason explanations, by arguing that they can have the explanatory force of ordinary causal explanations, without satisfying the presuppositions of ordinary causal explanations. As I have discussed in section III of this paper, Davidson has three quite different arguments for the causal theory. In one place he argues that reasons and actions must be related as cause and effect, since, otherwise, there is no way to express the difference between the case where an agent has a reason $R$, and does action $A$ because of $R$, and the case where the agent has a reason $R$, but does $A$ for another reason. In his opinion this establishes that reason explanations illustrate the same pattern of explanation as do ordinary causal explanations; but, as we appreciate because of Davidson, causality is one thing and causal explanation is another. He also argues that the causal theory is the only available account of the mysterious connection between reasons and actions. I have not been directly concerned here with whether Davidson's version of the causal theory is adequate on this point. In the third of his arguments for the causal theory, Davidson argues that reason explanations should be modeled on ordinary causal explanation, since the latter provides the only available option. As I have discussed here, the basic problem with Davidson's theory is that we gain our understanding of explanations of a given type by revealing their presuppositions. We cannot model reason explanations on ordinary causal explanations, if reason explanations do not satisfy the presuppositions of ordinary causal explanations.

Against the covering law model Davidson argues that one can causally explain events without referring to any laws (ARC, 16). His objection moves on two fronts. One is against the requirement that causal explanations include laws as part of the explanans. The second is against the requirement that explanations show why the event to be explained was to be expected. Even if both objections are valid, it does not follow that causal explanations do not presuppose a nomic nexus. One can agree with Davidson's stance against the covering law model, but argue, as I have, that ordinary causal explanations presuppose a nomic nexus.

Indeed, in a passage where he expresses the presuppositions of ordinary causal explanations, Davidson seems to contradict his claim that reason explanations could have the explanatory force of ordinary causal explanations:

\footnotetext{
We explain a broken window by saying that a brick broke it; what explanatory power the remark has derives from the fact that we may first expand the account of the cause to embrace an event, the movement of the brick, and we can then summon up evidence for the existence of a law connecting such events as motions of medium-sized rigid objects and the breaking of windows. The ordinary notion of cause is inseparable from this elementary form of explanation. ('Agency,' 52-3)
} 
The account of causal explanation offered above resembles the ontic conception, according to which causal explanations fit cause and effect into a nomic nexus expressed by laws or law-like generalizations. This is my contention: if reason explanations do not satisfy the presuppositions of ordinary causal explanations, they cannot illustrate the same pattern of explanation as do ordinary causal explanations. My argument says nothing about whether reasons and actions can be related as cause and effect. I also believe that Davidson's position on this point is inconsistent however. In the above passage, he claims that with ordinary causal explanations citing bricks and windows and the like, we can expand the account of cause and effect so as to invoke a background law; he also maintains that reason explanations do not fit reason and action into a nomic nexus. The latter point casts doubt on the idea that reasons fall under our ordinary notion of cause, if Davidson is right that, as he says above, 'the ordinary notion of cause is inseparable from this elementary form of explanation.' Depending upon how our ordinary notion of cause is logically related to our notion of ordinary causal explanation, it might be that the connection between reasons and actions cannot be construed as a relation of event causality, if reason explanations do not fit reason and action into a nomic nexus. That issue is worth pursuing.

In this paper I have not been directly concerned with the issue of whether the connection between reasons and actions should be construed as that of event causality. Instead, I have argued against Davidson's contention that reason explanations illustrate the same pattern of explanation as do ordinary causal explanations. If what I have said here is correct, then there are at least three attendant projects. One is a reevaluation of Davidson's arguments that the connection between reasons and actions is that of event causality. Another is a reevaluation of the view that reason explanations do not fit reason and action into a nomic nexus. ${ }^{16} \mathrm{~A}$ third, more ambitious project, is an investigation of the possibility for showing how the two basic intuitions underlying Davidson's version of the causal theory - the common-sense idea that an agent's reasons are causally relevant to the actions he or she performs and the Kantian idea that reason explanations do not fit reason and action into a nomic nexus - are compatible by providing a different account of the causal connection between reasons and actions than that

16 See, for example, Louise Anthony, 'Anomalous Monism and the Problem of Explanatory Force,' Philosophical Review 98 (1989) 153-87. 
of event causality. ${ }^{17}$ Since that causal relation would count as one of the presuppositions of any reason explanation, reason explanations would illustrate a pattern of causal explanation after all, but not one modeled on ordinary causal explanations. ${ }^{18}$

Received: June, 1992

Revised: October, 1993

Revised: May, 1994

17 Harry Frankfurt presents an interesting possibility for such a causal connection in 'The Problem of Action,' American Philosophical Quarterly 15 (1978) 157-62.

18 I am indebted to Tori McGeer, Bernie Katz, André Gombay, Mark Thornton, Betty Harlow, and the referees of the Canadian Journal of Philosophy for considerable advice. 